\title{
Tumor Vascularity Does Not Predict Response to Yttrium-90 Radioembolization for Hepatic Metastases from Colorectal Cancer
}

\author{
Alipi V. Naydenov ${ }^{1}$ William P. Harris ${ }^{2}$ Guy E. Johnson ${ }^{3}$
}

Daniel S. Hippe ${ }^{4}$ Siddharth A. Padia ${ }^{5}$

\begin{abstract}
Address for correspondence Siddharth A. Padia, MD, Division of Interventional Radiology, Department of Radiology, David Geffen School of Medicine at University of California, Los Angeles, 757 Westwood Plaza, Room 2125, Los Angeles, CA, 90095, United States (e-mail: spadia@gmail.com).
\end{abstract}

\begin{abstract}
Keywords

- radioembolization

- locoregional therapy

- liver-directed therapy

The purpose of this study was to determine whether the degree of tumor vascularity based on imaging has an impact on tumor response and survival in patients with metastatic colorectal cancer (mCRC) to the liver undergoing yttrium-90 radioembolization. A retrospective study of $75 \mathrm{mCRC}$ patients from a single-institution undergoing radioembolization was performed over a 7-year period. Tumors were categorized as hypo- or hypervascular based on digital subtraction angiography (DSA) and C-arm CT during mapping angiography. Tumor response and survival were compared between each group, after undergoing radioembolization. Hypervascular tumors were present in 37 of 75 (49\%) patients according to DSA. Of 37 patients who underwent C-arm CT during the procedure, $22(59 \%)$ had tumors classified as hypervascular. There were no significant differences in tumor response rates when vascularity was stratified by DSA or C-arm CT. Median progression-free survival (PFS) was 111 versus 128 days $(p=0.41)$ between DSA hypervascular and hypovascular cases, and median overall survival (OS) was 439 versus 342 days $(p=0.96)$. When stratified by $C$-arm CT, median PFS was 313 versus 244 days $(p=0.83)$ and median OS was 489 versus 342 days $(p=0.74)$ for hypervascular and hypovascular cases, respectively. Tumor vascularity based on DSA or C-arm CT does not predict imaging response or survival after radioembolization and should not be used as a criterion for selecting candidates for radioembolization for hepatic mCRC.
\end{abstract}

\section{Introduction}

Colorectal cancer (CRC) is the third most common cancer worldwide. ${ }^{1}$ Over one-half of patients with CRC develop metastases (mCRC), most commonly involving the liver., ${ }^{2,3}$
Liver metastases are the principal cause of morbidity and mortality in patients with mCRC. ${ }^{4,5}$ Though systemic chemotherapy is the standard treatment for stage IV colorectal cancer, the durability of this option is limited in the salvage setting. received

July 29, 2017

accepted after revision

September 29, 2017

published online

December 14, 2017
DOI https://doi.org/

10.1055/s-0037-1609046.

ISSN 2457-0214.
Copyright $@ 2018$ by Indian Society of

Vascular and Interventional Radiology
License terms

() (1) $\odot \circledast$ 
Yttrium-90 $\left({ }^{90} \mathrm{Y}\right)$ radioembolization has garnered increasing interest in controlling the growth of liver CRC metastases in patients who are not candidates for surgical resection or ablation. It is most frequently used in the salvage setting where randomized prospective trials have shown a 3-month survival advantage compared with standard chemotherapy. ${ }^{6}$ In a retrospective matched-pair cohort comparison, a 5-month survival advantage was demonstrated compared with best supportive care. ${ }^{7}$ Despite encouraging data, there remains a wide disparity in response for CRC patients undergoing radioembolization. The reasons for response differences have not been fully elucidated. Whereas absorbed radiation dose may impact tumor response and lead to improved outcomes, ${ }^{8}$ the assessment of baseline characteristics to better stratify patients is needed. Some early data with diffusion-weighted imaging have shown promise; however, magnetic resonance is not routinely obtained in patients with colorectal cancer at most centers. ${ }^{9}$ The presence of nonresponders in the mCRC population is particularly problematic for several reasons. The use of radioembolization in the early stage may delay the initiation of a patient's systemic chemotherapy. Furthermore, radioembolization may result in short- and long-term toxicity that may hinder further systemic therapy and survival. Therefore, effective stratification of patients as high- or low-likelihood responders remains an unmet need with potential to optimize clinical outcomes in patients with CRC liver metastases.

In a minimally embolic therapy such as radioembolization, increased tumor vascularity should theoretically correlate with better response due to more effective delivery of ${ }^{90} \mathrm{Y}$ microspheres into target tumors. The purpose of this study was to determine whether tumor vascularity predicted imaging response or survival in this setting.

\section{Methods}

\section{Patient Selection}

A retrospective study was conducted at a single institution by accessing the hospital's patient information system to identify all patients who underwent ${ }^{90} \mathrm{Y}$ radioembolization for hepatic mCRC between March 2008 and March 2015. This was collected into a database and approved by the hospital's institutional review board with waiver of informed consent.

All patients were discussed in a multidisciplinary liver tumor board. This board comprises medical oncologists, hepatobiliary surgeons, pathologists, radiation oncologists, diagnostic radiologists, and interventional radiologists. Radioembolization was not offered to patients who were candidates for surgical resection or thermal ablation. Patients were considered for radioembolization if they had liver-only or liver-dominant mCRC. Patients had either failed at least one line of chemotherapy or radioembolization was performed as an adjunct to first-line chemotherapy. A total of 89 patients were identified. Fourteen patients were excluded for incomplete records or lack of follow-up, leaving a total of 75 patients.

Prior to the procedure, all patients underwent baseline staging with a contrast-enhanced computed tomography (CT) of the chest, abdomen, and pelvis. Timing of abdominal imaging was performed in the portal venous phase (70-110 seconds after intravenous contrast administration). Imaging was obtained within 1 month of the mapping angiogram.

\section{Radioembolization}

Radioembolization was performed using standard methods with either glass (TheraSphere, BTG International) or resin (SirSphere, Sirtex) microspheres. This included a mapping angiogram with lung shunt fraction determination, ${ }^{90} \mathrm{Y} \mathrm{mi-}$ crosphere infusion, and posttherapy Bremsstrahlung single-photon emission computed tomography (SPECT)/CT. Device selection (glass vs. resin) was based on multiple factors, including operator preference, device availability at the study institution at the time of the procedure, and patients' medical insurance guidelines. If necessary, prophylactic coil embolization of extrahepatic arteries was performed to prevent nontarget radioembolization to extrahepatic structures (e.g., bowel). In all treatments, selective catheterization and infusion of the tumor-feeding arteries was performed whenever technically feasible. In cases of multifocal disease in which selective radioembolization was not feasible, a sequential lobar approach was taken.

For the mapping angiogram, a 4 or $5 \mathrm{~F}$ diagnostic catheter was used to select the visceral artery of interest (superior mesenteric and celiac arteries). Selective catheterization of the lobar hepatic arteries was performed with a $2.8 \mathrm{~F}$ coaxial microcatheter (Progreat, Terumo Medical Corporation). Digital subtraction angiography (DSA) was performed at three frames per second (Philips) with power injection of iodinated contrast (diluted to $50-70 \%$, depending on patient body habitus). Contrast injection was optimized to maximize tissue uptake without significant arterial reflux from the microcatheter tip position. Additional three-dimensional (3D) imaging of the abdomen was performed using C-arm CT with contrast injection via the microcatheter positioned within the lobar hepatic artery. Imaging was acquired over a 5-second timeframe with contrast injection occurring both prior to and during image acquisition. This allowed for enhancement to be identified both in the arterial and parenchymal phases. For glass microsphere dosimetry, an intended dose of 120 gray to the target perfused tissue was delivered. For resin microsphere dosimetry, activity was calculated based on the body-surface area formula, according to the package insert.

\section{Evaluation of Tumor Imaging Characteristics}

Radiologists blinded to patient information and outcome data reviewed imaging and categorized each tumor as hypo- or hypervascular according to ${ }^{1}$ baseline contrast-enhanced CT (portal venous phase), ${ }^{2}$ C-arm CT obtained during mapping angiography, and ${ }^{3}$ DSA during the mapping procedure. On baseline CT and C-arm CT, if the tumor enhanced to a greater degree than the surrounding hepatic parenchyma, it was categorized as hypervascular. Peripheral hypervascularity (with central hypoenhancement) was categorized as hypervascular. Conversely, if the tumor enhanced less than the surrounding parenchyma, it was categorized as hypovascular ( - Fig. 1). Likewise, for DSA, tumors 

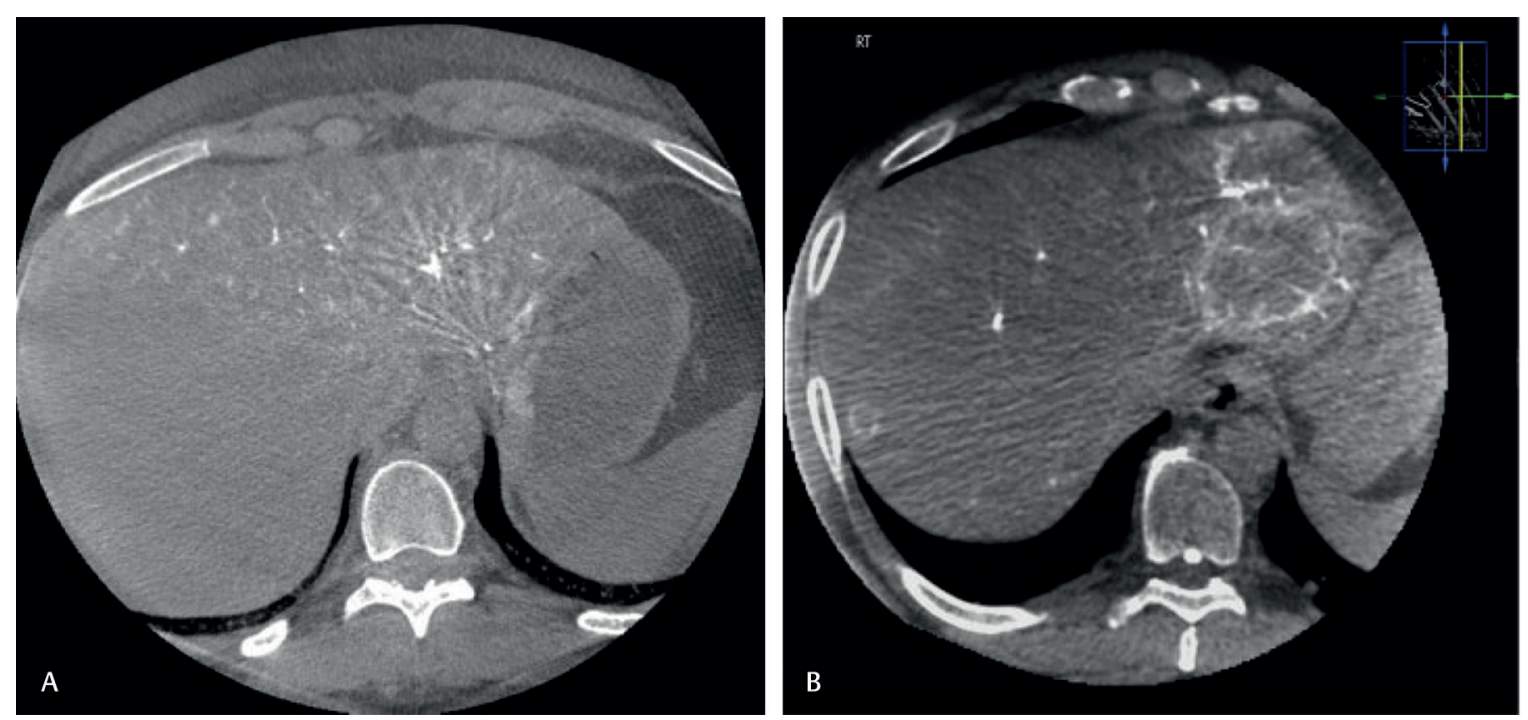

Fig. 1 C-arm CT during mapping angiogram with contrast injection from the left hepatic artery demonstrating (a) tumor hypovascularity and (b) tumor hypervascularity.

were categorized as hypo- or hypervascular based on the degree of vascularity relative to the surrounding hepatic parenchyma ( - Fig. 2).

\section{Patient Follow-up and Response Evaluation}

Follow-up visits and imaging (portal venous phase contrast-enhanced CT) took place 1 month following radioembolization and every 3 months thereafter. Toxicity was assessed according to Common Terminology Criteria for Adverse Events (CTCAE), version 4.0. ${ }^{10}$ Tumor response was categorized as complete response, partial response, stable disease, or progressive disease, according to Response Evaluation Criteria in Solid Tumors (RECIST) criteria version 1.1.11

\section{Statistical Analysis}

Categorical variables were summarized as number (percentage) and continuous variables as mean (interquartile range [IQR]) or median (range). Categorical variables were compared between vascularity groups using Fisher's exact test and continuous variables were compared between groups using the Mann-Whitney test. Overall survival (OS) and progression-free survival (PFS) were assessed using Kaplan-Meier curves. Index tumor progression was assessed using the cumulative incidence curve to account for the competing risk of death..$^{12}$ Median OS, PFS, and timeto-progression were estimated from these curves for each vascularity group. Event rates were compared between
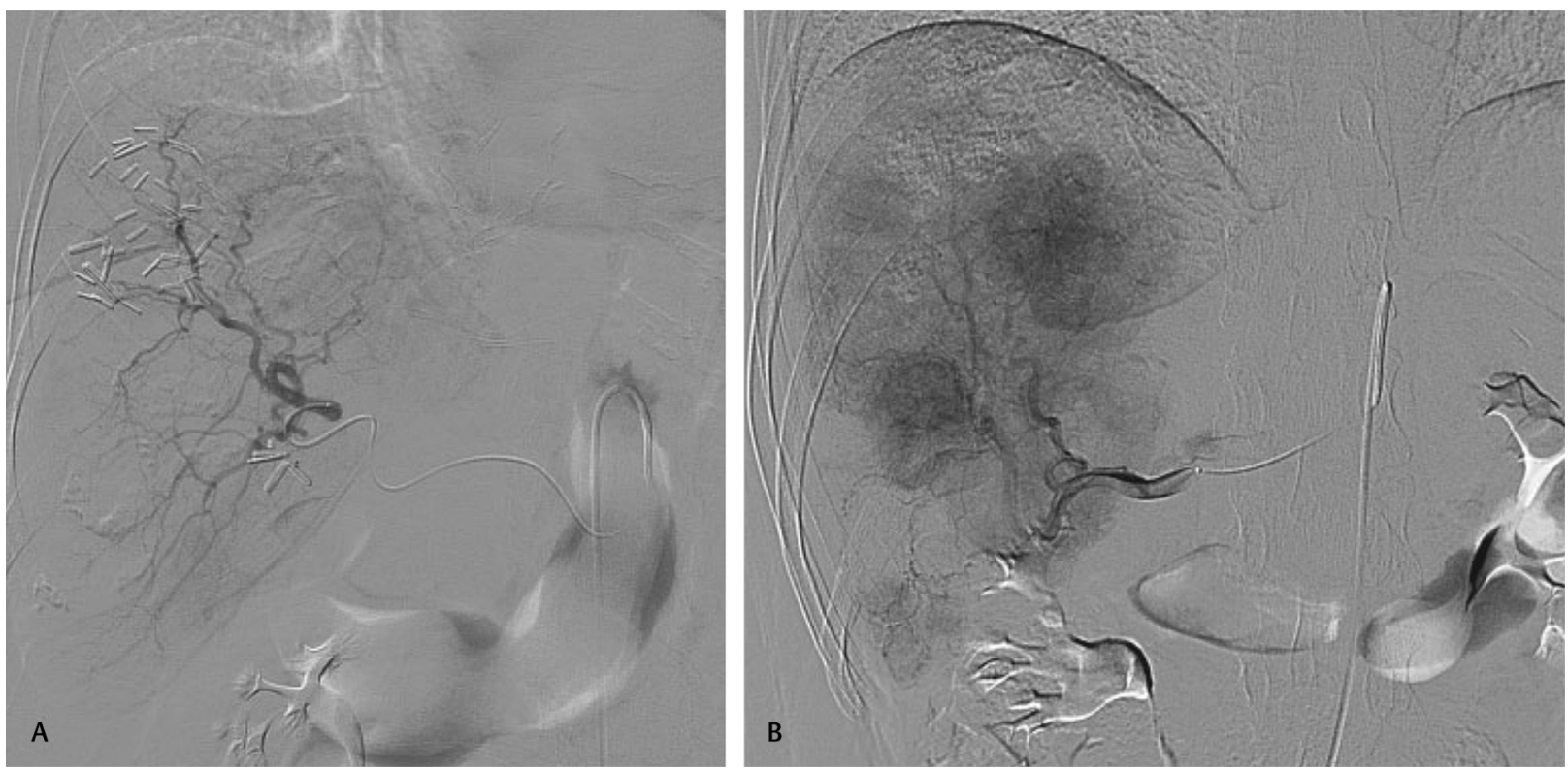

Fig. 2 Digital subtraction angiogram during mapping angiogram with contrast injection from the right hepatic artery demonstrating (a) tumor hypovascularity and (b) tumor hypervascularity. 
vascularity group using Cox proportional-hazard models (survival and progression-free survival) and the fine-gray proportion subdistribution hazard model (index tumor progression). ${ }^{13}$ Hazard ratios (HRs) were used to summarize differences in event rates between the vascularity groups; $95 \%$ confidence intervals (Cls) were used to assess the extent of the potential differences between vascularity groups. All statistical calculations were conducted with the statistical computing language $\mathrm{R}$ (version 3.1.1; R Foundation for Statistical Computing). Throughout, two-sided tests and CIs were used, with statistical significance defined as $p<0.05$.

\section{Results}

Seventy-five patients with mCRC treated with radioembolization were included. Patients' age ranged from 29 to 81 years (median, 57), and 55\% of the patient population was female (-Table 1). The colon was the primary site of malignancy in $79 \%$ of patients and rectum in $21 \%$ of patients; metastatic disease was diagnosed at the same time as the primary tumor in $73 \%$. KRAS mutation was identified in $63 \%$. The median follow-up time after treatment was 375 days (IQR: 186-614 days).

Of the 75 patients treated, 37 (49\%) had hypervascular tumors determined by DSA. Thirty-seven patients had C-arm CT imaging during mapping angiography, of which 22 (59\%) were classified as hypervascular and 15 (41\%) hypovascular. Patients who did not have C-arm CT were either due to lack of this technology in one of the angiography suites, or due to significant respiratory motion in which C-arm CT could not be performed. Although they were not available in all patients, C-arm CT images were available in a similar fraction of patients with hypervascular tumors per DSA as patients with hypovascular tumors ( $49 \%$ vs. $50 \%, p>0.99$ ). Of the 37 patients with both DSA and C-arm CT images, there was concordance of imaging hypervascularity in 29 (78\%).

Tumor vascularity was also examined on baseline contrast-enhanced CT. By CT, only 5 of 75 (7\%) patients' tumors were classified as hypervascular, all of which were concordant with DSA and C-arm CT. Because of the limited sample size of tumors classified as hypervascular by $\mathrm{CT}$, these classifications by baseline CT were not analyzed further.

Grouped according to vascularity, baseline patient characteristics are shown in - Table $\mathbf{1}$, and baseline tumor characteristics are shown in - Table 2 . There were no significant differences in baseline patient characteristics between patients who had hyper- or hypovascular tumors ( - Table 1 ), with the exception of the site of the primary tumor. The only tumor or treatment characteristic that differed significantly between hypo- and hypervascular tumors was the ${ }^{90} \mathrm{Y}$ device used ( $\boldsymbol{-}$ Table 2 ), where hypervascular tumors were more likely to be treated using glass microspheres than hypovascular tumors based on DSA and C-arm CT.

After treatment, most clinical complications and biochemical toxicities were uncommon, and not significantly different between the different groups of patients ( - Table 3 ). Of the 68 patients with imaging follow-up, $5.9 \%$ had a complete response by RECIST criteria. Though rates of complete response were higher in the hypovascular groups by DSA and C-arm CT, these differences did not reach statistical significance ( $\neg$ Table 4 ). There were no significant differences in OS (median: 439 vs. 342 days, $p=0.96$ ), PFS (median: 111 versus 128 days, $p=0.41$ ), or hepatic time-to-progression (median: 313 vs. 244 days, $p=0.83$ ) between DSA hyper- and hypovascular tumors ( - Fig. 3 ). The associated HRs are summarized in - Table 5. Results were not meaningfully changed after adjusting for the ${ }^{90} \mathrm{Y}$ device used.

Similarly, there were no significant differences in OS (median: 489 vs. 342 days, $p=0.74$ ), PFS (median: 100 vs. 152 days, $p=0.62$ ), or hepatic time-to-progression (median: 231 vs. 273 days, $p=0.42$ ) between C-arm CT hyper- and hypovascular tumors ( - Fig. 4 ). The associated HRs are summarized in - Table 6 .

\section{Discussion}

Growing evidence suggests that ${ }^{90} \mathrm{Y}$ radioembolization in addition to chemotherapy may be superior to chemotherapy alone for refractory liver mCRC. ${ }^{6,14-16}$ However, a subset of patients may experience toxicity or may fail to achieve hepatic tumoral stability or response. According to a recently published phase III trial, although addition of radioembolization to fluorouracil (5FU) increased the proportion of patients with stable disease from 35 to $76 \%$ and resulted in partial response in $10 \%$ of patients (compared with $0 \%$ in the 5FU-only group), there were still $10 \%$ of patients with disease progression after radioembolization. ${ }^{6}$ Similarly, prospective studies have reported that between 14.8 and $37 \%$ of patients have progressive disease despite radioembolization, and retrospective studies have reported as high as $23 \%$ progressive disease based on radiographic response. ${ }^{17}$ Therefore, it is reasonable to conclude that there is a sizeable portion of patients who do not benefit from radioembolization, and it remains an open question how this cohort can be identified a priori.

Several factors have been associated with poor outcomes after radioembolization. Two groups have reported that more than 3 prior lines of chemotherapy are associated with poor response to radioembolization. ${ }^{18,19}$ It is unclear whether this is a result of the effect of prior chemotherapy on the susceptibility of tumor tissue to radiotherapy, or if multiple prior lines of chemotherapy are simply a marker of aggressive tumors. Documented predictors of adverse outcomes after radioembolization include large hepatic burden of disease, extrahepatic disease, and lymph node involvement. ${ }^{17,18,20,21}$ Additional factors associated with adverse outcomes after radioembolization include elevated baseline tumor markers and rectal primary mCRC. ${ }^{18,20}$ Though multiple prognostic factors are likely required to identify appropriate patients for radioembolization, our study examines the potential utility of radiographic measures of tumor vascularity to augment patient selection.

This study demonstrates that tumor vascularity, as measured by C-arm CT and DSA, does not correlate with tumor response or survival. These data suggest that although 
Table 1 Patient characteristics by vascularity

\begin{tabular}{|c|c|c|c|c|c|c|c|c|}
\hline \multirow[b]{2}{*}{ Variable } & & \multirow[b]{2}{*}{$\begin{array}{l}\text { All } \\
(n=75)\end{array}$} & \multicolumn{2}{|c|}{ Vascularity by DSA } & \multirow[b]{2}{*}{$p$ Value $^{\mathrm{b}}$} & \multicolumn{2}{|c|}{ Vascularity by $\mathrm{C}$-arm $\mathrm{CT}^{\mathrm{a}}$} & \multirow[b]{2}{*}{$p$ Value $^{\mathrm{b}}$} \\
\hline & & & $\begin{array}{l}\text { Hypervascular } \\
(n=37)\end{array}$ & $\begin{array}{l}\text { Hypovascular } \\
(n=38)\end{array}$ & & $\begin{array}{l}\text { Hypervascular } \\
(n=22)\end{array}$ & $\begin{array}{l}\text { Hypovascular } \\
(n=15)\end{array}$ & \\
\hline \multirow[t]{2}{*}{ Sex } & Male & $34(45.3)$ & $15(40.5)$ & $19(50.0)$ & 0.49 & $7(31.8)$ & $9(60.0)$ & 0.11 \\
\hline & Female & $41(54.7)$ & $22(59.5)$ & $19(50.0)$ & & $15(68.2)$ & $6(40.0)$ & \\
\hline Age $(y)$ & & $57(29-81)$ & $57(30-81)$ & $58(29-75)$ & 0.71 & $57(35-72)$ & $55(30-75)$ & $>0.99$ \\
\hline \multirow[t]{3}{*}{ ECOG score } & 0 & $39(52.0)$ & $20(54.0)$ & $19(50.0)$ & $>0.99$ & 9 (40.9) & $10(66.7)$ & 0.39 \\
\hline & 1 & $31(41.3)$ & $15(40.5)$ & $16(42.1)$ & & $10(45.5)$ & $4(26.7)$ & \\
\hline & 2 & $5(6.7)$ & $2(5.4)$ & $3(7.9)$ & & $3(13.6)$ & $1(6.7)$ & \\
\hline \multirow[t]{2}{*}{ Primary tumor site ${ }^{c}$} & Colon & $57(79.2)$ & $31(86.1)$ & $26(72.2)$ & 0.25 & $20(90.9)$ & $5(38.5)$ & 0.002 \\
\hline & Rectum & $15(20.8)$ & $5(13.9)$ & $10(27.8)$ & & $2(9.1)$ & $8(61.5)$ & \\
\hline \multirow[t]{2}{*}{$\begin{array}{l}\text { Timing of hepatic } \\
\text { metastatis diagnosis }\end{array}$} & $\begin{array}{l}\text { Metachronous } \\
\text { with primary }\end{array}$ & $20(27.4)$ & $7(19.4)$ & $13(35.1)$ & 0.19 & $4(18.2)$ & $5(35.7)$ & 0.27 \\
\hline & $\begin{array}{l}\text { Synchronous } \\
\text { with primary }\end{array}$ & $53(72.6)$ & $29(80.6)$ & $24(64.9)$ & & $18(81.8)$ & $9(64.3)$ & \\
\hline \multirow[t]{2}{*}{$\begin{array}{l}\text { KRAS mutation } \\
\text { status }^{c}\end{array}$} & Wild type & $18(36.7)$ & 9 (37.5) & $9(36.0)$ & $>0.99$ & $8(44.4)$ & $4(36.4)$ & 0.72 \\
\hline & Mutant & $31(63.3)$ & $15(62.5)$ & $16(64.0)$ & & $10(55.6)$ & $7(63.6)$ & \\
\hline $\begin{array}{l}\text { Carcinoembryonic } \\
\text { antigen }^{c}\end{array}$ & & $32.6(1.2-1,658)$ & $32.6(1.2-1,658)$ & $28.2(1.5-993)$ & 0.48 & $28.9(1.8-694)$ & $81.8(2.4-993)$ & 0.41 \\
\hline Bilirubin & & $0.7(0.3-1.9)$ & $0.7(0.3-1.9)$ & $0.6(0.3-1.5)$ & 0.058 & $0.7(0.3-1.5)$ & $0.7(0.4-1.3)$ & 0.73 \\
\hline Albumin & & $3.7(1.1-4.5)$ & $3.8(1.1-4.5)$ & $3.6(2.0-4.3)$ & 0.53 & $3.8(1.1-4.5)$ & $3.5(2.7-4.3)$ & 0.36 \\
\hline
\end{tabular}

Abbreviations: CT, computed tomography; DSA, digital subtraction angiography; ECOG, Eastern Cooperative Oncology Group.

avalues are no. (\%) or median (range).

Fisher's exact test or the Mann-Whitney test.

cPatients with missing values for primary tumor site $(n=3)$, timing of diagnosis $(n=2)$, KRAS status $(n=26)$, or carcinoembryonic antigen ( $n=23)$ were excluded. 
Table 2 Tumor and treatment characteristics by vascularity

\begin{tabular}{|c|c|c|c|c|c|c|c|c|}
\hline \multirow[b]{2}{*}{ Variable } & & \multirow[b]{2}{*}{$\begin{array}{l}\text { All } \\
(n=75)\end{array}$} & \multicolumn{2}{|c|}{ Vascularity by angiography } & \multirow[b]{2}{*}{$p$ Value $^{\mathrm{b}}$} & \multicolumn{2}{|c|}{ Vascularity by $\mathrm{C}$-arm $\mathrm{CT}^{\mathrm{a}}$} & \multirow[b]{2}{*}{$p$ Value $^{\mathrm{b}}$} \\
\hline & & & $\begin{array}{l}\text { Hypervascular } \\
(n=37)\end{array}$ & $\begin{array}{l}\text { Hypovascular } \\
(n=38)\end{array}$ & & $\begin{array}{l}\text { Hypervascular } \\
(n=22)\end{array}$ & $\begin{array}{l}\text { Hypovascular } \\
(n=15)\end{array}$ & \\
\hline \multirow[t]{4}{*}{ No. of tumors } & 1 & $5(6.7)$ & $2(5.4)$ & $3(7.9)$ & 0.13 & $1(4.5)$ & $1(6.7)$ & 0.37 \\
\hline & $2-3$ & $11(14.7)$ & $9(24.3)$ & $2(5.3)$ & & $6(27.3)$ & $1(6.7)$ & \\
\hline & $4-5$ & $10(13.3)$ & $5(13.5)$ & $5(13.2)$ & & $4(18.2)$ & $2(13.3)$ & \\
\hline & $6+$ & $49(65.3)$ & $21(56.8)$ & $28(73.7)$ & & $11(50.0)$ & $11(73.3)$ & \\
\hline \multirow[t]{2}{*}{ Tumor distribution } & Bilobar & $62(82.7)$ & $29(78.4)$ & $33(86.8)$ & 0.38 & $18(81.8)$ & $13(86.7)$ & $>0.99$ \\
\hline & Unilobar & $13(17.3)$ & $8(21.6)$ & $5(13.2)$ & & $4(18.2)$ & $2(13.3)$ & \\
\hline $\begin{array}{l}\text { Long axis tumor (largest) dimen- } \\
\text { sion }(\mathrm{mm})\end{array}$ & & $44(14-140)$ & $48(15-130)$ & $40(14-140)$ & 0.39 & $49(23-130)$ & $34(14-119)$ & 0.16 \\
\hline Infiltrative tumor & & $8(10.7)$ & $5(13.5)$ & $3(7.9)$ & 0.48 & $3(13.6)$ & $2(13.3)$ & $>0.99$ \\
\hline Tumor burden > 50\% & & $7(9.3)$ & $2(5.4)$ & $5(13.2)$ & 0.43 & $2(9.1)$ & $2(13.3)$ & $>0.99$ \\
\hline Portal vein thrombus & & $4(5.3)$ & $2(5.4)$ & $2(5.3)$ & $>0.99$ & $2(9.1)$ & $1(6.7)$ & $>0.99$ \\
\hline Definite extrahepatic spread & & $13(17.3)$ & $5(13.5)$ & $8(21.1)$ & 0.54 & $5(22.7)$ & $5(33.3)$ & 0.71 \\
\hline \multirow[t]{4}{*}{ Prior liver treatment } & Resection & $19(25.3)$ & $11(29.7)$ & $8(21.1)$ & 0.44 & $6(27.3)$ & $2(13.3)$ & 0.43 \\
\hline & Ablation & $16(21.3)$ & $9(24.3)$ & $7(18.4)$ & 0.58 & $1(4.5)$ & $4(26.7)$ & 0.14 \\
\hline & Chemoembolization & $1(1.3)$ & $1(2.7)$ & $0(0.0)$ & 0.49 & $0(0.0)$ & $0(0.0)$ & $>0.99$ \\
\hline & $\begin{array}{l}\text { External beam } \\
\text { radiation }\end{array}$ & $2(2.7)$ & $1(2.7)$ & $1(2.6)$ & $>0.99$ & $1(4.5)$ & $1(6.7)$ & $>0.99$ \\
\hline \multirow[t]{4}{*}{ Prior lines of chemotherapy ${ }^{b}$} & 0 & $1(1.4)$ & $0(0.0)$ & $1(2.6)$ & 0.71 & $0(0.0)$ & $1(6.7)$ & 0.54 \\
\hline & 1 & $25(33.8)$ & $13(36.1)$ & $12(31.6)$ & & $10(45.5)$ & $4(26.7)$ & \\
\hline & 2 & $28(37.8)$ & $12(33.3)$ & $16(42.1)$ & & $8(36.4)$ & $7(46.7)$ & \\
\hline & $3-4$ & $20(27.0)$ & $11(30.6)$ & $9(23.7)$ & & $4(18.2)$ & $3(20.0)$ & \\
\hline Lung shunt fraction (\%) & & $3.1(1.0-12.4)$ & $3.0(1.0-12.4)$ & $3.2(1.2-9.8)$ & 0.71 & $3.3(1.0-12.4)$ & $3.2(2.0-9.8)$ & 0.99 \\
\hline \multirow[t]{2}{*}{${ }^{90} Y$ device infused } & Resin & $43(57.3)$ & $15(40.5)$ & $28(73.7)$ & 0.005 & $4(18.2)$ & $8(53.3)$ & 0.036 \\
\hline & Glass & $32(42.7)$ & $22(59.5)$ & $10(26.3)$ & & $18(81.8)$ & $7(46.7)$ & \\
\hline \multirow[t]{3}{*}{ Location of ${ }^{90} \mathrm{Y}$ infusions } & Right lobe only & $7(9.3)$ & $1(2.7)$ & $6(15.8)$ & 0.12 & $3(13.6)$ & $3(20.0)$ & 0.50 \\
\hline & Left lobe only & $31(41.3)$ & $18(48.6)$ & $13(34.2)$ & & $12(54.5)$ & $5(33.3)$ & \\
\hline & Both lobes & $37(49.3)$ & $18(48.6)$ & $19(50.0)$ & & $7(31.8)$ & $7(46.7)$ & \\
\hline
\end{tabular}

Abbreviation: CT, computed tomography.

avalues are no. (\%) or median (range).

'Fisher's exact test or the Mann-Whitney test.

cPatients with missing values for prior chemotherapy $(n=1)$, chemotherapy after ${ }^{90} \mathrm{Y}(n=14)$, or antiangiogenic agent after ${ }^{90} \mathrm{Y}(n=16)$ were excluded. 
Tumor Vascularity Does Not Predict Response to ${ }^{90}$ Y Radioembolization for Hepatic Metastases from CRC Naydenov et al. 9

Table 3 Short-term clinical and biochemical toxicity by vascularity

\begin{tabular}{|c|c|c|c|c|c|c|c|}
\hline & & Vascularity & $\mathrm{DSA}^{\mathrm{b}}$ & & Vascularit & y C-arm CT ${ }^{b}$ & \\
\hline Clinical toxicity ${ }^{\mathrm{a}}$ & $\begin{array}{l}\text { All } \\
(n=74)\end{array}$ & $\begin{array}{l}\text { Hyper } \\
(n=37)\end{array}$ & $\begin{array}{l}\text { Hypo } \\
(n=37)\end{array}$ & $p$ Value $^{c}$ & $\begin{array}{l}\text { Hyper } \\
(n=22)\end{array}$ & $\begin{array}{l}\text { Hypo } \\
(n=14)\end{array}$ & $p$ Value $^{c}$ \\
\hline Fatigue & $45(60.8)$ & $24(64.9)$ & $21(56.8)$ & 0.63 & $14(63.6)$ & $9(64.3)$ & $>0.99$ \\
\hline Pain & $12(16.2)$ & $6(16.2)$ & $6(16.2)$ & $>0.99$ & $3(13.6)$ & $4(28.6)$ & 0.39 \\
\hline Postembolization syndrome & $10(13.5)$ & $5(13.5)$ & $5(13.5)$ & $>0.99$ & $2(9.1)$ & $1(7.1)$ & $>0.99$ \\
\hline Hospital readmission within $30 \mathrm{~d}$ & $6(8.3)$ & $3(8.3)$ & $3(8.3)$ & $>0.99$ & $3(14.3)$ & $2(14.3)$ & $>0.99$ \\
\hline Ulcer & $5(6.8)$ & $1(2.7)$ & $4(10.8)$ & 0.36 & $0(0.0)$ & $0(0.0)$ & $>0.99$ \\
\hline Ascites & $4(5.4)$ & $3(8.1)$ & $1(2.7)$ & 0.61 & $2(9.1)$ & $0(0.0)$ & 0.51 \\
\hline Liver failure & $3(4.0)$ & $3(8.1)$ & $0(0.0)$ & 0.24 & $2(9.1)$ & $0(0.0)$ & 0.51 \\
\hline Death & $1(1.4)$ & $1(2.7)$ & $0(0.0)$ & $>0.99$ & $1(4.5)$ & $0(0.0)$ & $>0.99$ \\
\hline Encephalopathy & $0(0.0)$ & $0(0.0)$ & $0(0.0)$ & $>0.99$ & $0(0.0)$ & $0(0.0)$ & $>0.99$ \\
\hline Biloma & $0(0.0)$ & $0(0.0)$ & $0(0.0)$ & $>0.99$ & $0(0.0)$ & $0(0.0)$ & $>0.99$ \\
\hline Abscess & $0(0.0)$ & $0(0.0)$ & $0(0.0)$ & $>0.99$ & $0(0.0)$ & $0(0.0)$ & $>0.99$ \\
\hline Biochemical toxicity & All & DSA Hyper & DSA Hypo & & CT Hyper & СТ Hypo & \\
\hline$(\text { CTCAE grade } \geq 3)^{a}$ & $(n=70)$ & $(n=35)$ & $(n=35)$ & $p$ Value $^{c}$ & $(n=21)$ & $(n=14)$ & $p$ Value \\
\hline Any biochemical toxicity & $5(7.2)$ & $3(8.6)$ & $2(5.9)$ & $>0.99$ & $2(10.0)$ & $0(0.0)$ & 0.50 \\
\hline Hypoalbuminemia & $4(5.7)$ & $2(5.7)$ & $2(5.7)$ & $>0.99$ & $2(9.5)$ & $0(0.0)$ & 0.51 \\
\hline Increased total bilirubin & $2(2.9)$ & $2(5.7)$ & $0(0.0)$ & 0.49 & $2(10.0)$ & $0(0.0)$ & 0.50 \\
\hline Leukopenia & $1(1.4)$ & $1(2.9)$ & $0(0.0)$ & $>0.99$ & $0(0.0)$ & $0(0.0)$ & $>0.99$ \\
\hline Increased AST & $1(1.4)$ & $1(2.9)$ & $0(0.0)$ & $>0.99$ & $1(4.8)$ & $0(0.0)$ & $>0.99$ \\
\hline Increased ALT & $0(0.0)$ & $0(0.0)$ & $0(0.0)$ & $>0.99$ & $0(0.0)$ & $0(0.0)$ & $>0.99$ \\
\hline
\end{tabular}

Abbreviations: AST, aspartate aminotransferase; ALT, alanine transaminase; CT, computed tomography; CTCAE, Common Terminology Criteria for Adverse Events; DSA, digital subtraction angiography.

apatients with insufficient follow-up to assess clinical toxicity $(n=1)$, hospital readmission $(n=3)$, or biochemical toxicity $(n=5)$ were excluded.

bValues are no. (\%).

'Fisher's exact test.

biomarkers for high-likelihood radioembolization-responders remain in need, radiographic measures of tumor vascularity are unlikely to be of use for this purpose. Though these results are unexpected, they have potentially important consequences for patient selection for radioembolization.

There are several possible explanations for the results in this study. There is extensive literature to suggest that tissue oxygen is a radiosensitizer and that hypoxia is radioprotective. ${ }^{22-25}$ First, hypoxia is known to occur in many solid tumors and local hypoxia that may promote tumor angiogenesis. ${ }^{26}$ Therefore, there may not necessarily be a direct or predictable relationship between a tumor's vascularity and the partial pressure of oxygen $\left(\mathrm{PO}_{2}\right)$ in the tumor tissue. ${ }^{27}$ Indeed, if vascularity varies in concert with tissue metabolism, there may be no overall relation between vascularity and $\mathrm{PO}_{2}$ as demand may exceed supply. There is great

Table 4 Best response measured by RECIST criteria

\begin{tabular}{|c|c|c|c|c|c|c|c|c|}
\hline \multirow[b]{2}{*}{ Variable } & & \multirow[b]{2}{*}{$\begin{array}{l}\text { Alla } \\
(n=68)\end{array}$} & \multicolumn{2}{|c|}{ Vascularity by angiographyb } & \multirow[b]{2}{*}{$p$ Value $^{c}$} & \multicolumn{2}{|c|}{ Vascularity by $\mathrm{C}$-arm $\mathrm{CT}^{\mathrm{b}}$} & \multirow[b]{2}{*}{$p$ Value $^{c}$} \\
\hline & & & $\begin{array}{l}\text { Hyper } \\
(n=37)\end{array}$ & $\begin{array}{l}\text { Нуро } \\
(n=31)\end{array}$ & & $\begin{array}{l}\text { Hyper } \\
(n=22)\end{array}$ & $\begin{array}{l}\text { Нуро } \\
(n=12)\end{array}$ & \\
\hline \multirow[t]{4}{*}{ Best response } & CR & $4(5.9)$ & $1(2.7)$ & $3(9.7)$ & 0.55 & $1(4.5)$ & $2(16.7)$ & 0.74 \\
\hline & PR & $22(32.4)$ & $14(37.8)$ & $8(25.8)$ & & 7 (31.8) & $4(33.3)$ & \\
\hline & SD & $23(33.8)$ & $12(32.4)$ & $11(35.5)$ & & $8(36.4)$ & $3(25.0)$ & \\
\hline & PD & 19 (27.9) & $10(27.0)$ & $9(29.0)$ & & $6(27.3)$ & $3(25.0)$ & \\
\hline
\end{tabular}

Abbreviations: CR, complete response; CT, computed tomography; PR, partial response; PD, progression of disease; RECIST, Response Evaluation Criteria in Solid Tumors; SD, stable disease.

aPatients with insufficient imaging follow up $(n=7)$ were excluded.

bValues are no. (\%).

'Fisher's exact test. 


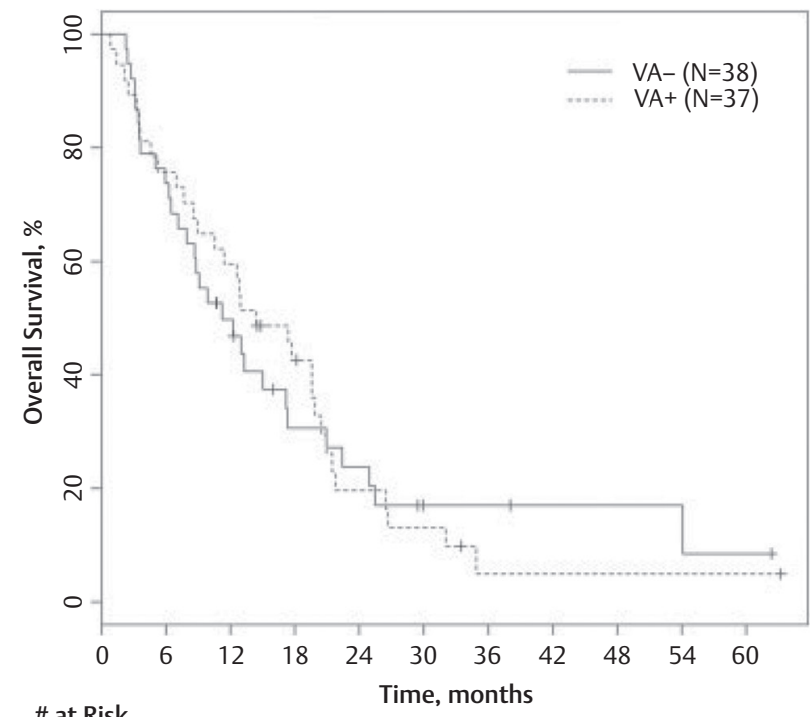

\# at Risk

VA+: $\begin{array}{lllllllllll}38 & 28 & 17 & 9 & 7 & 3 & 3 & 3 & 3 & 2 & 1\end{array}$

VA-: $\begin{array}{lllllllllll}37 & 28 & 22 & 14 & 6 & 4 & 1 & 1 & 1 & 1 & 1\end{array}$

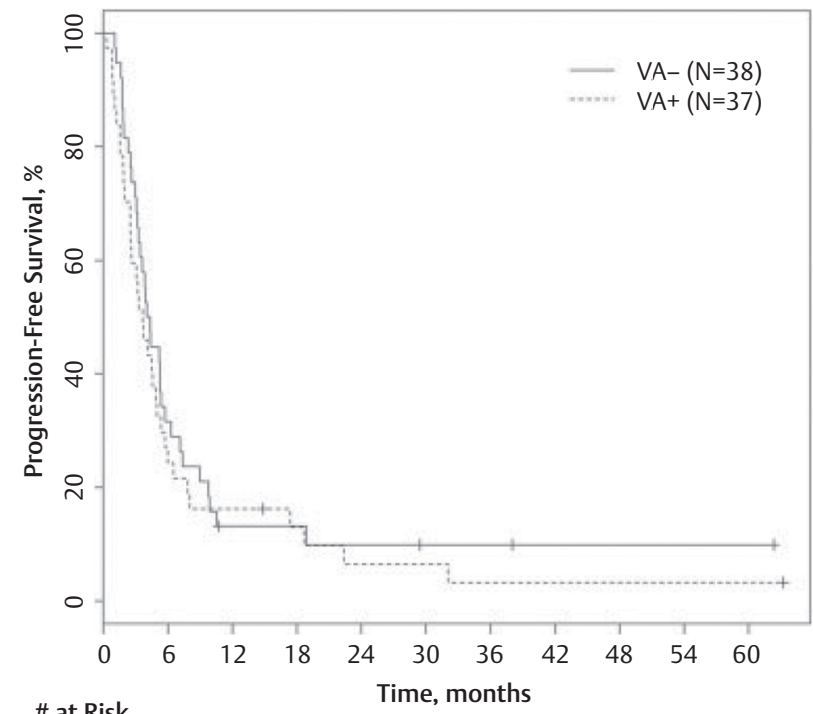

VA+: $\begin{array}{lllllllllll}38 & 12 & 4 & 4 & 3 & 2 & 2 & 1 & 1 & 1 & 1\end{array}$

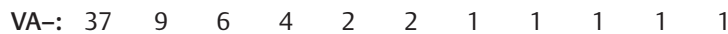

Fig. 3 Kaplan-Meier curves showing overall survival (left panel) and progression-free survival (right panel) for patients with hyper- and hypovascular lesions by DSA. Tick marks indicate censoring times. VA, vascularity by angiography.

Table 5 Differences in survival and progression between vascularity groups defined by DSA

\begin{tabular}{|l|l|l|l|l|l|l|}
\hline & \multicolumn{3}{|l|}{ Event incidence $^{\mathrm{a}}$} & \multicolumn{3}{l|}{} \\
\hline Event & No. & Hyper $(n=37)$ & Hypo $(n=38)$ & HR & $(95 \% \mathrm{Cl})$ & $p$ Value \\
\hline Death & 75 & $32(86.5)$ & $30(78.9)$ & 0.99 & $(0.60-1.63)$ & 0.96 \\
\hline Death or overall tumor progression & 75 & $35(94.6)$ & $34(89.5)$ & 1.22 & $(0.76-1.96)$ & 0.41 \\
\hline Index tumor progression & 68 & $22(61.1)$ & $22(68.8)$ & 0.94 & $(0.52-1.68)$ & 0.83 \\
\hline
\end{tabular}

Abbreviations: $\mathrm{Cl}$, confidence interval; $\mathrm{DSA}$, digital subtraction angiography; $\mathrm{HR}$, hazard ratio.

$\mathrm{HR}>1$ indicates hypervascular group is at higher risk than hypovascular group.

aValues are no. (\%); patients with insufficient imaging follow-up $(n=7)$ were excluded.

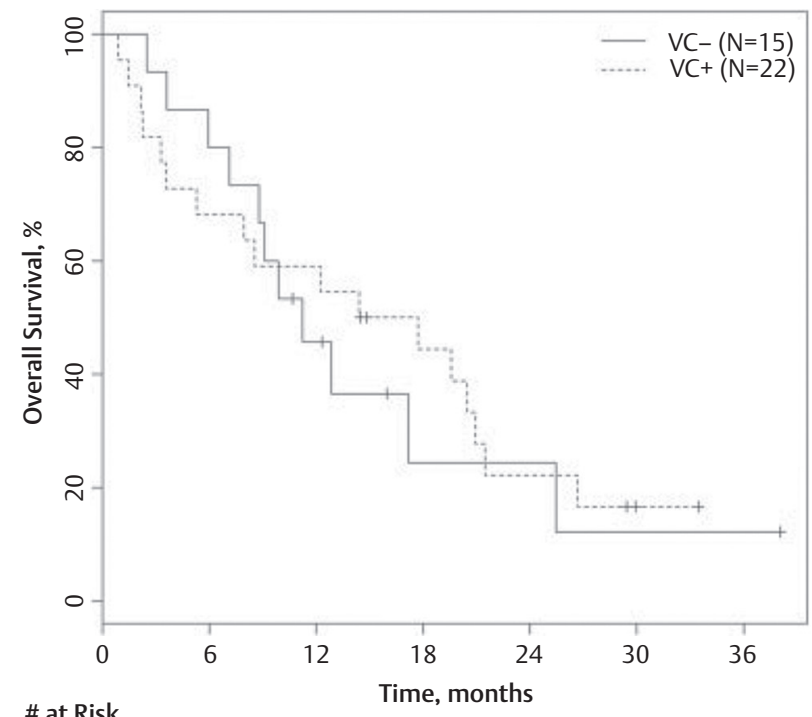

\# at Risk

VC+: 15

VC-: 22
126

15

3

2
8

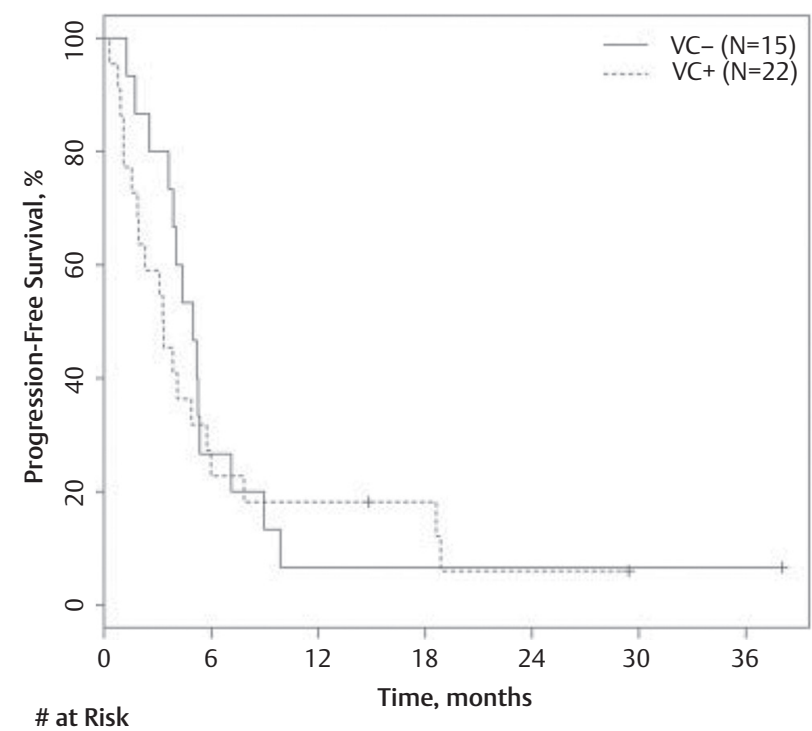

$\mathrm{VC+} \cdot 15$

VC-: 22

Fig. 4 Kaplan-Meier curves showing overall survival (left panel) and progression-free survival (right panel) for patients with hyper- and hypovascular lesions by C-arm CT. Tick marks indicate censoring times. VC, vascularity by c-carm CT. 
Table 6 Differences in survival and progression between vascularity groups defined by C-arm CT

\begin{tabular}{|c|c|c|c|c|c|c|}
\hline \multirow[b]{2}{*}{ Event } & \multirow[b]{2}{*}{ No. } & \multicolumn{2}{|c|}{ Event incidence $^{a}$} & \multirow[b]{2}{*}{$\mathrm{HR}$} & \multirow[b]{2}{*}{$(95 \% \mathrm{Cl})$} & \multirow[b]{2}{*}{$p$ Value } \\
\hline & & $\begin{array}{l}\text { Hyper } \\
(n=22)\end{array}$ & $\begin{array}{l}\text { Нуро } \\
(n=15)\end{array}$ & & & \\
\hline Death & 37 & $17(77.3)$ & $11(73.3)$ & 0.88 & $(0.40-1.90)$ & 0.74 \\
\hline Death or overall tumor progression & 37 & 20 (90.9) & $14(93.3)$ & 1.19 & $(0.6-2.38)$ & 0.62 \\
\hline Index tumor progressiona & 34 & $13(59.1)$ & $7(58.3)$ & 1.44 & $(0.60-3.47)$ & 0.42 \\
\hline
\end{tabular}

Abbreviations: $\mathrm{Cl}$, confidence interval; $\mathrm{HR}$, hazard ratio.

$\mathrm{HR}>1$ indicates hypervascular group is at higher risk than hypovascular group.

Values are no. (\%); patients with insufficient imaging follow up were excluded.

interest in the development of technology for imaging tumor hypoxia. ${ }^{28}$ Understanding the $\mathrm{PO}_{2}$ within target tumors may help with patient selection or dose planning for radioembolization. Whereas radioembolic particles may be more effectively delivered to hypervascular tumors, such tumors may be inherently more aggressive. Alternatively, additional unidentified components in the tumoral stroma and microenvironment may affect both vascularity and susceptibility to radiation.

Limitations to this study exist. This is a retrospective study, and therefore both patient selection and radioembolization device is nonuniform for the patient cohort. Second, though the assessment of vascularity was performed by a consensus of physicians who were blinded to the results, no standardized criteria currently exist for the scoring of tumor vascularity. Additionally, because CT images are acquired over an instant, the appearance of the vascularity of the tumor could be affected by the timing of the acquisition relative to the contrast material injection. Nevertheless, the CT protocol used reflects a relatively conventional method for portal venous phase timing, generalizable to other patient populations. Third, it is possible that hypervascular tumors may exhibit more aggressive behavior compared with hypovascular tumors. In that scenario, radioembolization could be more effective at treating (aggressive) hypervascular tumors than at treating (less aggressive) hypovascular tumors, leading to similar outcomes in two tumor populations that might behave differently without treatment.

\section{Conclusion}

In summary, this study concludes that radiographic measures of tumor vascularity correlate poorly with outcome after ${ }^{90} \mathrm{Y}$ radioembolization. Therefore, the degree of vascularity of a tumor should not impact candidacy for radioembolization given current evidence.

Financial Disclosures

AVN: None

WPH: Consultant for NeoTherma and Halozyme

SAP: Consultant for BTG International

DSH: None

GEJ: None

\section{Conflict of Interest}

There is no conflict of interest for any authors.

\section{Note}

This research did not receive any specific grant from funding agencies in the public, commercial, or not-for-profit sectors.

\section{References}

1 Ferlay J, Shin HR, Bray F, Forman D, Mathers C, Parkin DM. Estimates of worldwide burden of cancer in 2008: GLOBOCAN 2008. Int J Cancer 2010;127(12):2893-2917

2 Fong Y, Kemeny N, Paty P, Blumgart LH, Cohen AM. Treatment of colorectal cancer: hepatic metastasis. Semin Surg Oncol 1996;12(04):219-252

3 Steele G Jr, Ravikumar TS. Resection of hepatic metastases from colorectal cancer. Biologic perspective. Ann Surg 1989;210(02):127-138

4 Helling TS, Martin M. Cause of death from liver metastases in colorectal cancer. Ann Surg Oncol 2014;21(02):501-506

5 Wagner JS, Adson MA, Van Heerden JA, Adson MH, Ilstrup DM. The natural history of hepatic metastases from colorectal cancer. A comparison with resective treatment. Ann Surg 1984;199(05):502-508

6 Hendlisz A, Van den Eynde M, Peeters M, et al. Phase III trial comparing protracted intravenous fluorouracil infusion alone or with yttrium-90 resin microspheres radioembolization for liver-limited metastatic colorectal cancer refractory to standard chemotherapy. J Clin Oncol 2010;28(23):3687-3694

7 Seidensticker R, Denecke T, Kraus P, et al. Matched-pair comparison of radioembolization plus best supportive care versus best supportive care alone for chemotherapy refractory liver-dominant colorectal metastases. Cardiovasc Intervent Radiol 2012;35(05):1066-1073

8 Willowson KP, Hayes AR, Chan DLH, et al. Clinical and imaging-based prognostic factors in radioembolisation of liver metastases from colorectal cancer: a retrospective exploratory analysis. EJNMMI Res 2017;7(01):46

9 Schmeel FC, Simon B, Luetkens JA, et al. Prognostic value of pretreatment diffusion-weighted magnetic resonance imaging for outcome prediction of colorectal cancer liver metastases undergoing 90Y-microsphere radioembolization. J Cancer Res Clin Oncol 2017;143(08):1531-1541

10 National Cancer Institute. Common Terminology Criteria for Adverse Events v4.0. NCI, NIH, DHHS. May 29, 2009. NIH publication 09-7473

11 Eisenhauer EA, Therasse P, Bogaerts J, et al. New response evaluation criteria in solid tumours: revised RECIST guideline (version 1.1). Eur J Cancer 2009;45(02):228-247

12 Gooley TA, Leisenring W, Crowley J, Storer BE. Estimation of failure probabilities in the presence of competing risks: new representations of old estimators. Stat Med 1999;18(06):695-706

13 Fine JP, Gray RJ. A proportional hazards model for the subdistribution of a competing risk. J Am Stat Assoc 1999;94:496-509 
14 Van Hazel G, Blackwell A, Anderson J, et al. Randomised phase 2 trial of SIR-Spheres plus fluorouracil/leucovorin chemotherapy versus fluorouracil/leucovorin chemotherapy alone in advanced colorectal cancer. J Surg Oncol 2004;88(02):78-85

15 Sharma RA, Van Hazel GA, Morgan B, et al. Radioembolization of liver metastases from colorectal cancer using yttrium-90 microspheres with concomitant systemic oxaliplatin, fluorouracil, and leucovorin chemotherapy. J Clin Oncol 2007;25(09):1099-1106

16 Saxena A, Bester L, Shan L, et al. A systematic review on the safety and efficacy of yttrium-90 radioembolization for unresectable, chemorefractory colorectal cancer liver metastases. J Cancer Res Clin Oncol 2014;140(04):537-547

17 Nace GW, Steel JL, Amesur N, et al. Yttrium-90 radioembolization for colorectal cancer liver metastases: a single institution experience. Int J Surg Oncol 2011;2011:571261

18 Chua TC, Bester L, Saxena A, Morris DL. Radioembolization and systemic chemotherapy improves response and survival for unresectable colorectal liver metastases. J Cancer Res Clin Oncol 2011;137(05):865-873

19 Mulcahy MF, Lewandowski RJ, Ibrahim SM, et al. Radioembolization of colorectal hepatic metastases using yttrium-90 microspheres. Cancer 2009;115(09):1849-1858

20 Damm R, Seidensticker R, Ulrich G, et al. Y90 Radioembolization in chemo-refractory metastatic, liver dominant colorectal cancer patients: outcome assessment applying a predictive scoring system. BMC Cancer 2016;16:509

21 Stubbs RS, O'Brien I, Correia MM. Selective internal radiation therapy with $90 \mathrm{Y}$ microspheres for colorectal liver metastases: single-centre experience with 100 patients. ANZ J Surg 2006;76(08):696-703

22 Ling CC, Michaels HB, Gerweck LE, Epp ER, Peterson EC. Oxygen sensitization of mammalian cells under different irradiation conditions. Radiat Res 1981;86(02):325-340

23 Palcic B, Skarsgard LD. Reduced oxygen enhancement ratio at low doses of ionizing radiation. Radiat Res 1984; 100(02):328-339

24 Daşu A, Denekamp J. New insights into factors influencing the clinically relevant oxygen enhancement ratio. Radiother Oncol 1998;46(03):269-277

25 Wenzl T, Wilkens JJ. Modelling of the oxygen enhancement ratio for ion beam radiation therapy. Phys Med Biol 2011;56(11):3251-3268

26 Harris AL. Hypoxia-a key regulatory factor in tumour growth. Nat Rev Cancer 2002;2(01):38-47

27 Helmlinger G, Yuan F, Dellian M, Jain RK. Interstitial $\mathrm{pH}$ and $\mathrm{pO}_{2}$ gradients in solid tumors in vivo: high-resolution measurements reveal a lack of correlation. Nat Med 1997; 3(02):177-182

28 Krohn KA, Link JM, Mason RP. Molecular imaging of hypoxia. J Nucl Med 2008;49 (Suppl 2):129S-148S 